\title{
UCHENYE ZAPISKI TSAGI CELEBRATES ITS 50TH ANNIVERSARY
}

\author{
Sergei Leonidovich Chernyshev, Ivan Vladimirovich Egorov, \\ Gennadii Ashotovich Amyriyants, $\mathcal{E}$ \\ Valerii Nikolaevich Golubkin
}

Central Aerohydrodynamic Institute (TsAGI), 1, Zhukovsky Str., Zhukovsky, Moscow Region, 140180, Russian Federation, E-mail: uzts@tsagi.ru

This paper briefly describes the history of Uchenye Zapiski TsAGI since 1970, when the journal was founded.

KEY WORDS: Uchenye Zapiski TsAGI journal, TsAGI Science Journal, 50th anniversary, Central Aerohydrodynamic Institute, aviation and space science, industrial aerodynamics, hydrodynamics

January 2020 marks 50 years since the first issue of the journal Uchenye Zapiski TsAGI (TsAGI Scientific Notes) was published. The journal was founded in 1970 due to the initiative of a group of TsAGI scientists, and is a periodical of the Zhukovsky Central Aerohydrodynamic Institute. Professor A.A. Nikolsky was its first chief editor. Currently, this role is performed by the TsAGI Chief Scientific Officer and Academician of the Russian Academy of Sciences, S.L. Chernyshev. The Editorial Board of the journal includes leading scientists and specialists at TsAGI, the Central Research Institute for General Machine Building, Central Institute of Aviation Motors, Moscow Aviation Institute, and a number of prominent foreign scientists.

Uchenye Zapiski TsAGI publishes original scientific papers by scientists at TsAGI and other organizations in the field of mechanics and control processes as part of fundamental and applied research on problems related to the progress of aviation and space science, industrial aerodynamics, and hydrodynamics. This includes relevant issues in relation to fluid, gas, and plasma mechanics; aerodynamics; flight and solid mechanics; and strength and structural vibrations under hydro-gasdynamics, thermal, and other physical influences. Significant emphasis is given to mathematical modeling of real processes and optimization problems. One of the main objectives of the journal is to familiarize a wide range of specialists with theoretical and experimental research methods, which can form the basis of effective engineering approaches to aircraft design. These areas are balanced and presented to the Editorial Board of the journal. Reviewers of incoming articles are also leading experts in various fields of aeromechanics; mainly doctors of the sciences. 
The journal Uchenye Zapiski TsAGI is intended for scientists and engineers working in research institutes and universities, aviation design bureaus, and aerospace industries. Over the past half century of regular and fruitful work, Uchenye Zapiski TsAGI has published a large number of academic papers of fundamental and applied importance. Among them, the following pioneering studies in the field of aeromechanics should be mentioned. These include the studies by A.A. Nikolsky on the theory of inviscid separation; G.I. Taganov and V.S. Sadovsky on the theory of vortex separated flows; V.V. Sychev and V.Ya. Neyland on the theory of separated flows of viscous liquid and gas; Yu.L. Zhilin and S.L. Chernyshev on the sonic boom from supersonic aircraft; V.G. Mikeladze on the theory and practice of aerodynamic experiments; Ya.M. Serebrisky and G.A. Pavlovets on airfoil theory; M.N. Kogan and V.N. Zhigulev on physical gas dynamics; M.F. Pritulo on the aerodynamics of rockets; V.A. Yaroshevsky and V.A. Ilyin on flight mechanics and optimization; A.F. Selikhov and Yu.A. Stuchalkin on the aircraft structural strength theory; V.P. Kolgan, I.V. Petukhov, and I.V. Egorov on the development of new computational aerodynamics methods; A.M. Gaifullin on the extension of vortex filaments; I.I. Lipatov and V.Ya. Neyland on the theory of unsteady separation and interaction of the boundary layer with a supersonic gas flow; and many other studies that have established new scientific areas. Most of the aforementioned studies are presented in [1].

Uchenye Zapiski TsAGI is a peer-reviewed publication, it is included in the list of scientific periodicals on aviation and aerospace recognized by the Higher Attestation Commission, and it publishes articles by applicants for scientific degrees of candidates and doctors of sciences in relevant disciplines. The journal is included in the catalog of the Federal Agency on Press and Mass Communications and is open for subscription.

Currently, the journal is undergoing significant updating, aimed at fuller compliance with modern requirements and increasing its prestige and role in the development of aerospace science and technology. Since 2009, the frequency of the journal, as in the first 30 years, has been at least six issues per year, with strict adherence being given to the deadlines for issuing the journal and the duration of the entire article cycle. Since 2009, in collaboration with Begell House, Inc. (www.begellhouse.com) Uchenye Zapiski TsAGI has been published in the United States as TsAGI Science Journal, which is a complete English translation of the Russian language journal. It is included in the database of the Russian Science Citation Index (RSCI: www.e-library.ru) in order to ensure the availability of all journal issues in electronic form and to have a competitive impact factor. Uchenye Zapiski TsAGI publishes selected proceedings of conferences held with the participation of TsAGI (with thorough scientific review and editing of articles). A website for the journal has been developed, where one can find annotations of all published articles. The Editorial Board of the journal continues to develop the traditions laid down by its first members, which are presented in Fig. 1.

Congratulations are extended to the long-standing, regular authors and readers of the journal, as well as to those who are just discovering it, as we celebrate the 50th anniversary of Uchenye Zapiski TsAGI. We invite all scientists and engineers directly related to the subject matter of Uchenye Zapiski TsAGI to take an active part in the publication of their most significant scientific results, as well as in the use of journal materials for the development of aerospace science and technology.

\section{REFERENCES}

1. TsAGI Science Journal, vol. 49, no. 4, 2018. 


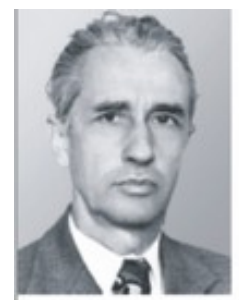

Bushgens G.S.

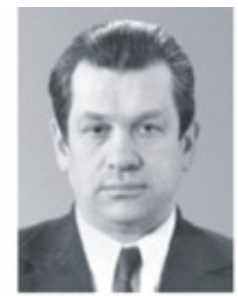

Ilyin V.A. (responsible secretan)

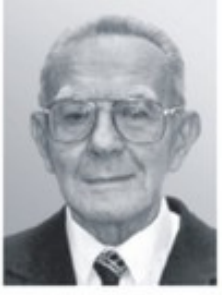

Ginevskyi A.S.

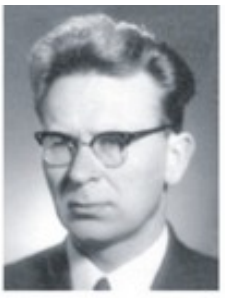

Ilyichev V.D.

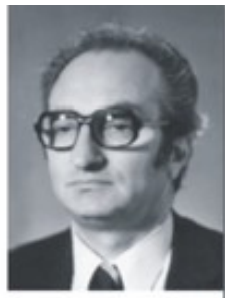

Kogan M.N.

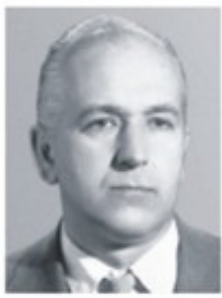

Kuriyanov A.I

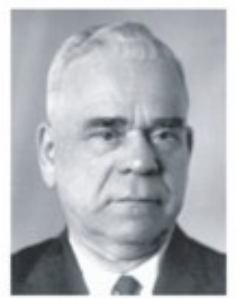

Makarevskii A.I.

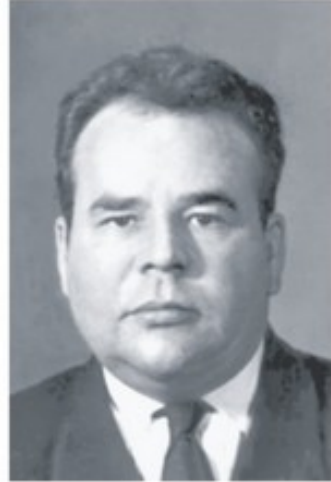

Nikolsky A.A.
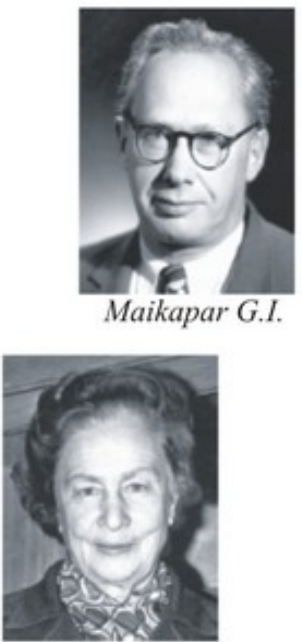

Melegi O.V.

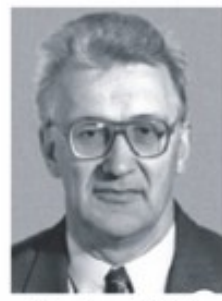

Neyland V. Ya.

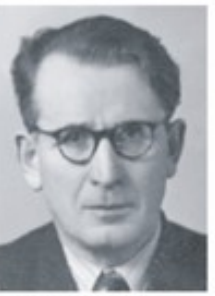

Strelkov $S . P$

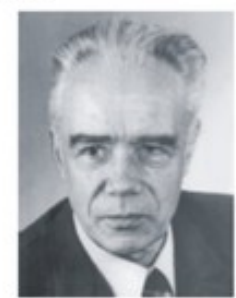

Svischev G.P.

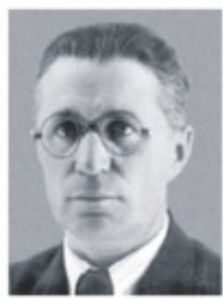

Simonov L.A.

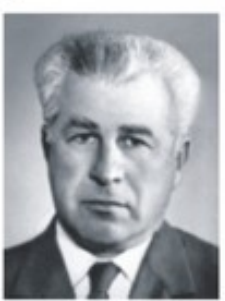

Serebryisky Ya. M.

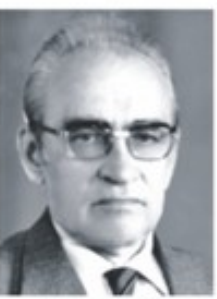

Sychev V.V.

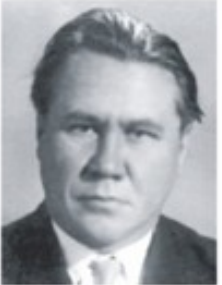

Taganov G.I.

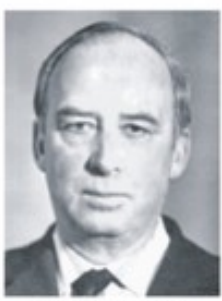

Frolov V.M.

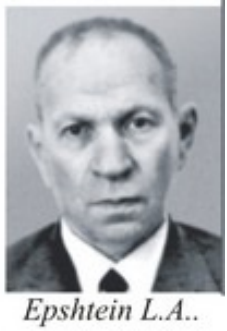

FIG. 1: The first members of the Editorial Board of Uchenye Zapiski TsAGI 